\title{
Bacterial pyruvate production from alginate, a promising carbon source from marine brown macroalgae.
}

\section{AUTHOR(S):}

Kawai, Shigeyuki; Ohashi, Kazuto; Yoshida, Shiori; Fujii, Mari; Mikami, Shinichi; Sato, Nobuyuki; Murata, Kousaku

\section{CITATION:}

Kawai, Shigeyuki ...[et al]. Bacterial pyruvate production from alginate, a promising carbon source from marine brown macroalgae.. Journal of bioscience and bioengineering 2014, 117(3): 269-274

\section{ISSUE DATE:}

2014-03

URL:

http://hdl.handle.net/2433/182900

\section{RIGHT:}

(C) 2013 The Society for Biotechnology, Japan. Published by Elsevier B.V.; この論文は出版社版でありません。引用の際には出版社版をご確 認ご利用ください。; This is not the published version. Please cite only the published version. 
1 Bacterial pyruvate production from alginate, a promising carbon source from

2 marine brown macroalgae

3

4 Running title: Bacterial pyruvate production from alginate

5

6 Shigeyuki Kawai, ${ }^{1,}$ Kazuto Ohashi, ${ }^{1}$ Shiori Yoshida, ${ }^{1}$ Mari Fujii, ${ }^{1}$

7 Shinichi Mikami, ${ }^{1}$ Nobuyuki Sato, ${ }^{2}$ Kousaku Murata ${ }^{1}$

8

$9{ }^{1}$ Laboratory of Basic and Applied Molecular Biotechnology, Division of Food and

10 Biological Science, Graduate School of Agriculture, Kyoto University, Uji, Kyoto

11 611-0011, Japan

$12{ }^{2}$ Central Research Institute, Maruha Nichiro Holdings, Inc., 16-2, Wadai, Tsukuba,

13 Ibaraki, 300-4295, Japan

14

$15{ }^{*}$ Corresponding author.

$16 \quad$ Tel. +8177438 3768; fax. +81774383767 .

17 E-mail address: kawais@kais.kyoto-u.ac.jp

18

19 Key words: Sphingomonas sp.; alginate; pyruvate; macroalgae; marine biomass

20 
1 Abstract

Marine brown macroalgae is a promising source of material for biorefining,

3 and alginate is one of the major components of brown algae. Despite the huge

4 potential availability of alginate, no system has been reported for the production of

5 valuable compounds other than ethanol from alginate, hindering its further utilization.

6 Here we report that a bacterium, Sphingomonas sp. strain A1, produces pyruvate from

7 alginate and secretes it into the medium. High aeration and deletion of the gene for

8 D-lactate dehydrogenase are critical for the production of high concentrations of

9 pyruvate. Pyruvate concentration and productivity were at their maxima (4.56 g/l and

$1095.0 \mathrm{mg} / \mathrm{l} / \mathrm{h}$, respectively) in the presence of $5 \%(\mathrm{w} / \mathrm{v})$ initial alginate, whereas

11 pyruvate produced per alginate consumed and \% of theoretical yield $(0.19 \mathrm{~g} / \mathrm{g}$ and

$1218.6 \%$, respectively) were at their maxima at $4 \%(\mathrm{w} / \mathrm{v})$ initial alginate. Concentration

13 of pyruvate decreased after it reached its maximum after cultivations for 2 or 3 days at

14145 strokes per minute. Our study is the first report to demonstrate the production of

15 other valuable compounds than ethanol from alginate, a promising marine macroalgae

16 carbon source. 


\section{Introduction}

Among red, green, and brown marine macroalgae, brown macroalgae are

3 the largest and therefore the most desirable sources for biorefining. Macroalgae have

4 several advantages as a crop: they are more productive than land crops; do not require

5 arable land, irrigation water, or fertilizer; and they contain no lignin. (1-4). One of the

6 major components in brown algae is alginate: the brown algae Laminaria japonica

7 and genera Sargassum and Turbinaria contain up to $40 \%$ alginate by dry weight $(5,6)$.

8 Alginate is a linear polysaccharide consisting of $\beta$-D-mannuronate $(\mathrm{M})$ and its $\mathrm{C} 5$

9 epimer $\alpha$-L-guluronate $(\mathrm{G})$, arranged as polyM, polyG, and heteropolymeric random 10 sequences (polyMG) (7).

Two systems for ethanol production from alginate have been established using bioengineered bacteria, including Sphingomonas sp. strain A1 (8) and

13 Escherichia coli (9). The former system depends on the ethanologenic Sphingomonas 14 sp. strain A1, which lacks the gene for D-lactate dehydrogenase (LDH) and also 15 carries the genes for pyruvate decarboxylase (PDC) and alcohol dehydrogenase 16 (ADH) from Zymomonas mobilis on a broad-host-range plasmid pKS13 (10); this strain can produce up to $13 \mathrm{~g} / \mathrm{l}$ ethanol from alginate (8). The latter system is 18 dependent on an ethanologenic E. coli strain carrying genes for alginate utilization, 19 PDC, $\mathrm{ADH}$, and containing several deletions; this strain can produce $37 \mathrm{~g} / 1$ ethanol 20 from a mixture of mannitol and alginate derived from brown algae (kombu;

21 Saccharina japonica) (9). Although these systems for ethanol production from 22 alginate have been established $(8,9)$, no system has been reported for the production 23 of valuable compounds other than ethanol from alginate. 
1 employed for production of crop-protection agents, polymers, cosmetics, and food

2 additives (11). Chemical production of pyruvate has been achieved by dehydration

3 and decarboxylation of tartrate (12). However, this process is not cost-effective (11);

4 hence, biotechnological pyruvate production has attracted attention. To date,

5 successful biotechnological production of pyruvate has primarily proceeded from

6 glucose, using bacteria such as E. coli and Corynebacterium glutamicum and yeasts such as Saccharomyces cerevisiae and Torulopsis glabrata (11, 13-15).

In Sphingomonas sp. strain A1, alginate is depolymerized by endo- and

9 exo-alginate lyases into unsaturated uronic acid, which is non-enzymatically 10 converted to 4-deoxy-L-erythro-5-hexoseulose uronic acid (DEH) (Fig. 1). DEH is

11 reduced to non-toxic 2-keto-3-deoxy-D-gluconate and metabolized to pyruvate, which 12 could be further metabolized via the TCA cycle $(16,17)$ (Fig. 1). In ethanologenic 13 Sphingomonas sp. strain A1, pyruvate is converted into ethanol by PDC and ADH (8).

14 In this study, we found that Sphingomonas sp. strain A1 that lacks LDH gene secretes 15 pyruvate into the medium, thus opening the door to marine biorefineries that could 16 cost-effectively produce several valuable compounds from marine biomass.

MATERIALS AND METHODS

Strain and cultivation The Sphingomonas sp. A1 wild type (WT) strain

21 is a Gram-negative bacterium that is able to assimilate alginate (16). The LDH gene of Sphingomonas sp. A1 WT strain was disrupted by inserting kanamycin-resistant cassette into LDH gene on the genome, resulting in the Sphingomonas sp. A1 ldh

24 strain (MK2651) (8). Strain MK3567 is the Sphingomonas sp. A1 ldh strain carrying 25 an empty broad host range plasmid, pKS13 (10). 
Alginate medium contains sodium alginate (from brown algae; average MW,

$2300 \mathrm{kDa}$; ratio of $\mathrm{M}$ to $\mathrm{G}, 3: 1$; Nacalai Tesque, Japan), $0.1 \% \mathrm{w} / \mathrm{v}\left(\mathrm{NH}_{4}\right)_{2} \mathrm{SO}_{4}, 0.1 \%$

$3 \mathrm{w} / \mathrm{v} \mathrm{KH}_{2} \mathrm{PO}_{4}, 0.1 \% \mathrm{w} / \mathrm{v} \mathrm{Na}_{2} \mathrm{HPO}_{4}, 0.01 \% \mathrm{w} / \mathrm{v} \mathrm{MgSO}_{4} \cdot 7 \mathrm{H}_{2} \mathrm{O}, 0.01 \% \mathrm{w} / \mathrm{v}$ yeast extract

4 ( $\mathrm{pH} 8.0)$ (8). For cultivation of MK3567, $20 \mathrm{mg} / 1$ tetracycline (Tet) and $25 \mathrm{mg} / \mathrm{l}$

5 kanamycin (Kan) were included in the media; for cultivation of MK2651, $25 \mathrm{mg} / 1$

6 Kan alone was included. For solid medium, alginate medium containing $0.5 \% \mathrm{w} / \mathrm{v}$

7 alginate was solidified with $1.5 \% \mathrm{w} / \mathrm{v}$ agar. For precultivation, fresh A1 bacteria

8 grown on alginate solid medium were inoculated into liquid alginate medium

9 containing $0.8 \% \mathrm{w} / \mathrm{v}$ alginate and precultured at $30^{\circ} \mathrm{C}$ for $24 \mathrm{~h}$ at 145 strokes per

10 minute (spm) on a Personal Lt-10F shaking water bath (Taitec, Japan). Cells in the

11 preculture were inoculated into $100 \mathrm{ml}$ liquid alginate medium containing $5 \% \mathrm{w} / \mathrm{v}$ 12 alginate (5\% alginate medium) in a 300-ml Erlenmeyer flask (MK3567) or in $20 \mathrm{ml}$

13 liquid alginate media containing $0.8,2,3,4,5$, or $6 \% \mathrm{w} / \mathrm{v}$ alginate $(0.8,2,3,4,5$, or $146 \%$ alginate medium) in a $200-\mathrm{ml}$ flask (WT and MK2651), to reach an $\mathrm{OD}_{600}$ of 0.1 ; 15 bacteria were then cultivated further at $30^{\circ} \mathrm{C}$ at 50,95 , or $145 \mathrm{spm}$, unless otherwise 16 specified. The supernatant of the culture was harvested after centrifugation of the 17 culture at $20,000 \times \mathrm{g}$, at $4^{\circ} \mathrm{C}$ for $5 \mathrm{~min}$. Cell dry weight (CDW) of Sphingomonas sp. 18 A1 was calculated from the $\mathrm{OD}_{600}$ using a ratio of $0.38 \mathrm{~g}(\mathrm{CDW}) \mathrm{l}^{-1}$ per $\mathrm{OD}_{600}$. This 19 ratio was obtained from 4 experiments in which MK2651 strain was cultivated in 20 liquid $100 \mathrm{ml}$ alginate medium containing $0.8 \% \mathrm{~W} / \mathrm{v}$ alginate in a $300-\mathrm{ml}$ flask at $30^{\circ} \mathrm{C}$ 21 and 145 spm for 1 day.

Metabolome analysis Metabolome analysis of the supernatant of the

24 cultures described above was performed by Human Metabolome Technologies, Inc., 
using capillary-electrophoresis time-of-flight mass spectrometry (CE-TOFMS) in the anion and cation detection modes (8).

3

HPLC analysis For the analyses of pyruvate, 2-oxoglutarate, and 2-oxoisovalerate, HPLC analysis was conducted using an HPLC equipped with an Aminex HPX-87H column $(300 \times 7.8 \mathrm{~mm}$; Bio-Rad, USA $)$ and a RID-10A detector (Shimadzu, Japan). Other conditions were as follows: effluent, filtered and degassed 5 $\mathrm{mM} \mathrm{H}_{2} \mathrm{SO}_{4}$; flow rate, $0.65 \mathrm{ml} \mathrm{min}^{-1}$; column temperature, $65.5^{\circ} \mathrm{C}$.

\section{Concentration of oxygen in liquid medium Concentration of oxygen}

11 dissolved in liquid medium was measured using a Fibox 3 oxygen sensor (Presens, Regensburg, Germany) and an oxygen-sensor spot (Presens) attached to the bottom of a 300-ml Erlenmeyer flask. In this study, the saturated concentration of oxygen dissolved in liquid medium at $30^{\circ} \mathrm{C}$ was considered to be $7.5 \mathrm{mg} / \mathrm{l}(18)$.

TLC analysis Authentic compounds $(5 \mu 1,2 \% \mathrm{w} / \mathrm{v}$ sucrose or glucose) and the cultures $(5 \mu \mathrm{l})$ were spotted onto TLC glass plates with silica gel $60 \mathrm{~F}_{254}$ (Merck, USA), dried, developed with a solvent system consisting of 1-butanol, acetate, and water $(3: 2: 2, \mathrm{v} / \mathrm{v} / \mathrm{v})$ and visualized by heating the TLC plate at $130^{\circ} \mathrm{C}$ for $5 \mathrm{~min}$ after spraying it with $10 \%(\mathrm{v} / \mathrm{v})$ sulfuric acid in ethanol (17).

21

Other analytical methods The concentration of pyruvate in the 4-day supernatants of initial cultivation of MK3567 strain was determined with metabolome or HPLC analysis as above. In the other case, the concentration of pyruvate of the supernatant of the culture was determined using pyruvate assay kit (Roche 
1 Diagnostics). A standard curve was prepared for each assay. Alginate concentrations

2 in the cultures were determined by the carbazole sulfuric acid method, using sodium

3 alginate as the standard (19).

4 
RESULTS AND DISCUSSION

Production of pyruvate by Sphingomonas sp. strain A1 Metabolome

analysis of the intracellular compounds of the Sphingomonas sp. A1 WT strain has been previously described (8). In the previous analysis, the WT strain was cultivated in liquid alginate medium containing $0.5 \%$ or $3 \% \mathrm{w} / \mathrm{v}$ alginate, and intracellular accumulation of lactate was observed (8).

In this study, we performed metabolome analysis of the supernatants of the Sphingomonas sp. A1 ldh strain carrying an empty plasmid pKS13 (10) (MK3567) cultivated in $100 \mathrm{ml}$ liquid alginate medium containing $5 \% \mathrm{w} / \mathrm{v}$ alginate in $300-\mathrm{ml}$

11 Erlenmeyer flasks for 1, 2, or 4 days at 95 spm (Table 1). The Sphingomonas sp. A1 ldh strain is the host for the ethanologenic Sphingomonas sp. A1 and lacks the LDH gene (8). The $l d h$ strain still shows approximately $20 \%$ of LDH activity compared to WT strain (8). We initially conducted this analysis as a control for the analysis of the supernatants of ethanologenic Sphingomonas sp. A1 strain. The ethanologenic strain is Sphingomonas sp. A1 ldh strain carrying PDC genes and ADH gene on a broad host range plasmid pKS13 (8). This is the reason why we initially used the $l d h$ strain carrying pKS13 (MK3567), not ldh strain without plasmid (MK2651).

Of the 61 metabolites that were quantitatively identified, only pyruvate and 2-oxoglutarate exceeded $10 \mathrm{mM}$; pyruvate concentrations were 1.2, 20.2, and 26.2 $\mathrm{mM}(0.11,1.8$, and $2.3 \mathrm{~g} / 1$, respectively), and 2-oxoglutarate concentrations were 0.09 , 1.6 , and $14.4 \mathrm{mM}(0.01,0.23$, and $2.1 \mathrm{~g} / \mathrm{l}$, respectively), in supernatants of 1,2 , and

23 4-days cultures. 2-Oxoisovalerate was the compound that was produced in the third 24 highest amounts: $0.018,1.2$, and $2.5 \mathrm{mM}(0.00,0.14$, and $0.29 \mathrm{~g} / 1$, respectively) in 1 , 2, and 4-day cultures. 
Because pyruvate has been regarded as an intermediate in the

2 alginate-metabolic pathway $(16,17)$ (Fig. 1), we did not expect to detect high

3 concentrations of extracellular pyruvate. Due to high industrial demand for pyruvate

4 (11) and the huge potential availability of alginate as source for biorefining, we chose

5 to further characterize pyruvate production from alginate using Sphingomonas sp.

6 strain A1.

\section{Aeration is important for the production of pyruvate from alginate}

Sphingomonas sp. A1 ldh strain carrying an empty plasmid pKS13 (MK3567) was

10 cultivated under the same conditions used for metabolome analysis, but at 50, 95, or

$11145 \mathrm{spm}$ for 4 days, during which we monitored the concentrations of oxygen, pyruvate, and alginate and the growth of this strain. The culture was aerated highly at $145 \mathrm{spm}$, moderately at $95 \mathrm{spm}$, and slightly at $50 \mathrm{spm}$.

Oxygen concentrations of the culture were kept at basal levels during cultivation at 50 and $95 \mathrm{spm}$, whereas the concentration increased to saturation at 6.0-7.5 mg/l at $145 \mathrm{spm}$ (Fig. 2a). Cultivation at $145 \mathrm{spm}$ also gave the maximum concentrations of pyruvate, whereas cultivation at $95 \mathrm{spm}$ and $50 \mathrm{spm}$ resulted in moderate and no pyruvate production, respectively. Growth was in accord with the pyruvate production, and consumption of alginate was lowest at $50 \mathrm{spm}$, but approximately equal at 95 and $145 \mathrm{spm}$. Thus, high aeration is important for pyruvate

21 production. The 4-day supernatants were also analyzed by HPLC, and the maximum 22 production of pyruvate at $145 \mathrm{spm}$ was again confirmed $(3.33,0.49$, and $0 \mathrm{~g} / \mathrm{l}$

23 pyruvate at 145,95 , and $50 \mathrm{spm}$; data not shown). At 145, 95, and $50 \mathrm{spm}$, production

24 of 2-oxoglutarate $(0.87,0.14$, and $0 \mathrm{~g} / \mathrm{l})$ was lower than that of pyruvate, and no 25 production of 2-oxoisovalerate was detected (data not shown). 
3 determine the optimum initial concentration of alginate, Sphingomonas sp. A1 ldh

4 strain (MK2651) that carries no plasmid was cultivated at $145 \mathrm{spm}$ in $20 \mathrm{ml}$ liquid

5 alginate media containing $0.8,2,3,4,5$, or $6 \%$ alginate in 200-ml Erlenmeyer flasks

6 for 6 days, during which we measured the concentrations of pyruvate and alginate and

7 the growth of this strain (Fig. 3). Productivity $(\mathrm{mg} / \mathrm{l} / \mathrm{h}), \mathrm{Y}_{\mathrm{P} / \mathrm{S}}(\mathrm{g} / \mathrm{g})$ (an yield of

8 pyruvate produced $[\Delta P ; \mathrm{g} / \mathrm{l}]$ per alginate consumed $[\Delta S ; \mathrm{g} / \mathrm{l}]), \%$ of theoretical yield,

$9 \operatorname{CDW}(\Delta X ; \mathrm{g} / \mathrm{l}), \mathrm{Y}_{\mathrm{X} / \mathrm{S}}(\mathrm{g} / \mathrm{g})($ an yield of CDW $[\Delta X ; \mathrm{g} / \mathrm{l}]$ per alginate consumed $[\Delta S$;

$10 \mathrm{~g} / \mathrm{l}]), \mathrm{Y}_{\mathrm{P} / \mathrm{X}}(\mathrm{g} / \mathrm{g})$ (an yield of pyruvate produced $[\Delta P ; \mathrm{g} / \mathrm{l}]$ per $\mathrm{CDW}[\Delta X ; \mathrm{g} / \mathrm{l}]$ ) were

11 calculated based on the obtained data. Theoretical yield was taken to be $100 \%$ when

$12100 \mathrm{~g}$ pyruvate was produced from $100 \mathrm{~g}$ consumed alginate, because 2 mol of 13 pyruvate (MW of 88) is theoretically produced from $1 \mathrm{~mol}$ of DEH (MW of 176) (Fig. $141)$.

As shown in Fig. 3 and Table 2, only a limited amount of pyruvate was produced in alginate medium containing $0.8 \% \mathrm{w} / \mathrm{v}$ alginate, whereas pyruvate concentration $(\Delta P ; \mathrm{g} / \mathrm{l})$ and productivity $(\mathrm{mg} / \mathrm{l} / \mathrm{h})$ were at their maxima in the presence of $5 \%$ initial alginate. $\mathrm{Y}_{\mathrm{P} / \mathrm{S}}(\mathrm{g} / \mathrm{g})$ and $\%$ of theoretical yield were at their maxima at $4 \%$ initial alginate. $\operatorname{CDW}(\Delta X ; \mathrm{g} / \mathrm{l})$ and $\mathrm{Y}_{\mathrm{X} / \mathrm{S}}(\mathrm{g} / \mathrm{g})$ were at their maxima at $3 \%$ initial alginate. $Y_{P / X}(g / g)$ was at its maximum at $6 \%$ initial alginate. Growth rates over 2 days were higher in 2 and 3\% alginate media than other media (Fig. 3c). Consumption of alginate was also confirmed by TLC (Fig. 3d).

24 Fig. 3a, Table 2) was higher than those observed in Fig. 2 b (2.80 g/l), although cells were cultivated in liquid $5 \%$ alginate medium at $145 \mathrm{spm}$ at $30^{\circ} \mathrm{C}$ in both cases. We 
1 attributed this to differences between the strains (MK3567 and MK2651 strains) and

2 the scales of the cultures. In Fig. 2, Sphingomonas sp. A1 MK3567 strain (the ldh

3 strain carrying an empty plasmid pKS13) was cultivated in $100 \mathrm{ml}$ medium in 300-ml

4 Erlenmeyer flasks, whereas Sphingomonas sp. A1 MK2651 strain (the ldh strain

5 without plasmid) was cultivated in $20 \mathrm{ml}$ medium in 200-ml flasks in Fig. 3.

6

Effect of LDH disruption on production of pyruvate This study was undertaken with the Sphingomonas sp. A1 ldh strains (MK3567 and MK2651 strains), which is host of the ethanologenic Sphingomonas sp. strain A1 (8). Since pyruvate is a substrate of $\mathrm{LDH}$, disruption of $\mathrm{LDH}$ could enhance production of pyruvate. To confirm this, we compared production of pyruvate by the WT strain (Fig. 4, open symbols) at $145 \mathrm{spm}$ in liquid alginate medium containing $5 \% \mathrm{w} / \mathrm{v}$ alginate to production by Sphingomonas sp. A1 ldh strain (MK2651) without plasmid (Fig. 4, closed symbols; Table 2). Although the consumption rates of alginate and growth of the $l d h$ strain were approximately the same as those of the WT (Fig. 4, b and d), the maximum pyruvate concentration of WT strain was lower than that of the $l d h$ strain (Fig. 4a). Moreover, concentration of pyruvate dropped rapidly in the WT strain (Fig. 4a). In accord with its lower production of pyruvate, the WT strain produced D-lactate, whereas the $l d h$ strain produced only a limited amount of D-lactate (Fig. 4c). No production of L-lactate was observed in either the WT or ldh strains (Fig. 4c). These data demonstrate that disruption of the LDH gene clearly increased pyruvate production. 
1 whereas that of D-lactate did not decrease and remained saturated during cultivation

2 (Fig. 2b, Fig. 3a, and Fig. 4ac), suggesting that Sphingomonas sp. strain A1 utilizes

3 pyruvate, but not D-lactate, as a carbon source. Accordingly, we observed that the

4 Sphingomonas sp. A1 WT strain utilized pyruvate as a carbon source, but not

5 D-lactate or other organic acids (citrate, succinate, L-lactate, D-Lactate, fumarate,

6 L-malate, DL-isocitrate, and acetate); this strain grew better in the presence of 7 pyruvate than in the presence of glucose (Fig. 5a).

Moreover, we demonstrated that Sphingomonas sp. A1 ldh strain (MK2651)

9 metabolized both alginate and pyruvate; both of which were utilized simultaneously

10 (Fig. 5c). When alginate was present alone at a concentration of $0.8 \%(\mathrm{w} / \mathrm{v})$, it was

11 more rapidly consumed by the $l d h$ strain than $0.8 \%(\mathrm{w} / \mathrm{v})$ pyruvate alone or $0.8 \%$

$12(\mathrm{w} / \mathrm{v})$ alginate and $0.8 \%(\mathrm{w} / \mathrm{v})$ pyruvate (Fig. 5c), indicating that pyruvate partially

13 suppresses the utilization of alginate. Growth of the $l d h$ strain in the presence of both

$14 \quad 0.8 \%(\mathrm{w} / \mathrm{v})$ alginate and $0.8 \%(\mathrm{w} / \mathrm{v})$ pyruvate was approximately the same as in the

15 presence of $0.8 \%(\mathrm{w} / \mathrm{v})$ alginate alone, but faster than in the presence of $0.8 \%(\mathrm{w} / \mathrm{v})$

16 pyruvate alone (Fig. 5c). We also investigated whether the $l d h$ strain would produce

17 pyruvate in $5 \%(\mathrm{w} / \mathrm{v})$ alginate medium initially containing $0.5 \%(\mathrm{w} / \mathrm{v})[5.0 \mathrm{~g} / \mathrm{l}]$

18 pyruvate, and compared the results with those obtained from the $l d h$ strain cultivated

19 in $5 \%(\mathrm{w} / \mathrm{v})$ alginate medium with no initial pyruvate (Fig. 5d). We observed that the

20 concentration of pyruvate dropped rapidly and never exceeded $5.0 \mathrm{~g} / \mathrm{l}$, and that

21 alginate was utilized more moderately than in the absence of initial pyruvate (Fig. $5 \mathrm{~d}$ ).

22 These observations demonstrate that pyruvate partially suppresses not only utilization

23 of alginate as shown in Fig. 5c, but also production of pyruvate.

24 Collectively, we propose that when the Sphingomonas sp. A1 WT strain

25 metabolizes alginate, it secretes pyruvate and reutilizes the secreted pyruvate, which 
could partially suppress further utilization of alginate. This could at least partially explain why Sphingomonas sp. A1 ldh strain ceased to utilize alginate after 2-3 days during production of pyruvate from alginate (Fig. 2c, 3b).

Furthermore, we surmise that Sphingomonas sp. strain A1 produce the cellular structure molecules from pyruvate such as through gluconeogenesis and pentose-phosphate pathways. Sphingomonas sp. strain A1 contains all genes for gluconeogenesis and pentose-phosphate pathways on its genome (our unpublished data). However, the reason why other organic acids than pyruvate could not be the carbon source has remained to be elucidated. It should be noted that Sphingomonas sp. strain A1 carries the genes for TCA cycle and in particular the gene that shows $54 \%$ identity (e value of e-130) with detA (Escherichia coli C4-dicarboxylic acid transporter) (20).

(1)

Toward production of higher amounts of pyruvate by Sphingomonas sp.

strain A1 Several studies have reported the production of pyruvate from glucose by microorganisms, including the yeast $S$. cerevisiae IFO0538 (37 g/l pyruvate) (11), the yeast T. glabrata IFO0005 (68 g/l) (11), engineered E. coli (62 g/l) (14), and engineered C. glutamicum (44 g/l) (13); these systems produced more pyruvate than our system in this study produced from alginate. However, the literature regarding the production of pyruvate from carbon sources other than glucose is limited $(11,13,14)$; no studies have reported production of pyruvate from alginate.

Growth of the Sphingomonas sp. A1 WT and ldh strains was not inhibited by extracellular pyruvate up to $\sim 12 \mathrm{~g} / 1$ (Fig. $5 \mathrm{~b}$ ). Thus, the $l d h$ strain could produce at least $\sim 12 \mathrm{~g} / 1$ pyruvate as a result of several genetic modifications such as that relieves the partial suppression of alginate utilization by pyruvate, described above. In 
1 addition, other genetic modifications could enhance tolerance of extracellular

2 pyruvate.

As noted above, pyruvate is widely used in agriculture and industry (11);

4 because pyruvate is an important intermediate in metabolic map, several valuable

5 compounds could be produced from it. Furthermore, alginate is abundant and widely

6 available. Therefore, the use of alginate to produce pyruvate could be of tremendous

7 economic importance. Our study is the first report demonstrating the production of a

8 valuable compound from alginate, opening the way to marine biorefineries that could

9 cost-effectively produce several compounds from marine biomass, a promising carbon 10 source.

ACKNOWLEDGEMENTS

This work was supported by the Funding Program for Next-Generation

14 World-Leading Researchers (NEXT Program) (to S.K).

References

17 1. Huesemann, M., Roesjadi, G., Benemann, J., and Metting, F. B.: Biofuels from microalgae and seaweeds, p. 165-184. In Vertès, A., Qureshi, N., Yukawa, H., and Blaschek, H. P. (ed.), Biomass to

21 2. Adams, J. M., Gallagher, J. A., and Donnison, I. S.: Fermentation study on Saccharina latissima for bioethanol production considering variable pre-treatments, J. Appl. Phycol., 21, 569-574 (2009). 
3. Yoon, J. J., Kim, Y. J., Kim, S. H., Ryu, H. J., Choi, J. Y., Kim, G. S., and

Shin, M. K.: Production of polysaccharides and corresponding sugars from red seaweed, Adv. Mat. Res., 93-94, 463-466 (2010).

4. John, R. P., Anisha, G. S., Nampoothiri, K. M., and Pandey, A.: Micro and macroalgal biomass: a renewable source for bioethanol, Bioresour. Technol., 102, 186-193 (2011). Monthly determination of alginate, $\mathrm{M} / \mathrm{G}$ ratio, mannitol, and minerals in cultivated Laminaria Japonica, Nippon Suisan Gakkaishi, 59, 295-299 (1993).

7. Gacesa, P.: Alginates, Carbohydr. Polym., 8, 161-182 (1988).

8. Takeda, H., Yoneyama, F., Kawai, S., Hashimoto, W., and Murata, K.: Bioethanol production from marine biomass alginate by genetically engineered bacteria, Energy Environ. Sci., 4, 2575-2581 (2011).

9. Wargacki, A. J., Leonard, E., Win, M. N., Regitsky, D. D., Santos, C. N., Kim, P. B., Cooper, S. R., Raisner, R. M., Herman, A., Sivitz, A. B., Lakshmanaswamy, A., Kashiyama, Y., Baker, D., and Yoshikuni, Y.: An engineered microbial platform for direct biofuel production from brown macroalgae, Science, 335, 308-313 (2012).

10. Kimbara, K., Hashimoto, T., Fukuda, M., Koana, T., Takagi, M., Oishi, M., and Yano, K.: Cloning and sequencing of two tandem genes involved in degradation of 2,3-dihydroxybiphenyl to benzoic acid in the polychlorinated 
biphenyl-degrading soil bacterium Pseudomonas sp. strain KKS102, J. Bacteriol., 171, 2740-2747 (1989).

11. Li, Y., Chen, J., and Lun, S. Y.: Biotechnological production of pyruvic acid, Appl. Microbiol. Biotechnol., 57, 451-459 (2001).

12. Howard, J. W., and Fraser, W. A.: Preparation of pyruvic acid, Org. Synth. Coll., 1, 475-480 (1932).

13. Wieschalka, S., Blombach, B., and Eikmanns, B. J.: Engineering Corynebacterium glutamicum for the production of pyruvate, Appl. Microbiol.

14. Wendisch, V. F., Bott, M., and Eikmanns, B. J.: Metabolic engineering of Biotechnol., 94, 449-459 (2012).

16. Murata, K., Kawai, S., Mikami, B., and Hashimoto, W.: Superchannel of

15. Wieschalka, S., Blombach, B., Bott, M., and Eikmanns, B. J.: Bio-based production of organic acids with Corynebacterium glutamicum, Microb. Biotechnol., 6, 87-102 (2013).

18. Truesdale, G. A., Downing, A. L., and Lowden, G. F.: The solubility of oxygen in pure water and sea-water, J. Appl. Chem., 5, 53-62 (1955). 
1 19. Galambos, J. T.: The reaction of carbazole with carbohydrates. I. Effect of borate and sulfamate on the carbazole color of sugars, Anal. Biochem., 19, 119-132 (1967).

4 20. Davies, S. J., Golby, P., Omrani, D., Broad, S. A., Harrington, V. L., 5 Guest, J. R., Kelly, D. J., and Andrews, S. C.: Inactivation and regulation of the aerobic $\mathrm{C}_{4}$-dicarboxylate transport $(d c t A)$ gene of Escherichia coli, J. Bacteriol., 181, 5624-5635 (1999).

8 
$1 \quad$ Figure legends

2 FIG. 1. Alginate metabolism in the Sphingomonas sp. A1 wild-type strain $(16,17)$.

3 Compounds are indicated in bold, and enzymes are in gray. Abbreviations: DEH,

4 4-deoxy-L-erythro-5-hexoseulose uronic acid; KDG, 2-keto-3-deoxy-D-gluconate;

5 KDGP, 2-keto-3-deoxy-phosphogluconate; GAP, glyceraldehyde 3-phosphate; A1-R,

6 NADPH-dependent DEH reductase; A1-K, KDG kinase; A1-A, aldolase; LDH,

$7 \quad$ D-lactate dehydrogenase.

9 FIG. 2. Aeration is important for the production of pyruvate from alginate.

10 Concentrations of oxygen (a), pyruvate (b), alginate (c), and growth (d; OD 600$)$ of the

11 culture of the Sphingomonas sp. A1 ldh strain carrying pKS13 (MK3567). This strain was cultivated at 50 (circles), 95 (squares), and 145 (triangles) spm in $100 \mathrm{ml} \mathrm{5 \%}$ liquid alginate medium [5\% w/v alginate, $0.1 \% \mathrm{w} / \mathrm{v}\left(\mathrm{NH}_{4}\right)_{2} \mathrm{SO}_{4}, 0.1 \% \mathrm{w} / \mathrm{v} \mathrm{KH}_{2} \mathrm{PO}_{4}$, $0.1 \% \mathrm{w} / \mathrm{v} \mathrm{Na}_{2} \mathrm{HPO}_{4}, 0.01 \% \mathrm{w} / \mathrm{v} \mathrm{MgSO}_{4} \cdot 7 \mathrm{H}_{2} \mathrm{O}, 0.01 \% \mathrm{w} / \mathrm{v}$ yeast extract $(\mathrm{pH} 8.0), 20$ $\mathrm{mg} / \mathrm{l} \mathrm{Tet}$, and $25 \mathrm{mg} / \mathrm{l} \mathrm{Kan}]$ in $300-\mathrm{ml}$ Erlenmeyer flasks at $30^{\circ} \mathrm{C} . \mathrm{b}-\mathrm{d}$; Averages and standard deviations (SD) of three independent experiments are shown.

FIG. 3. Effect of initial concentration of alginate on production of pyruvate. The

19 Sphingomonas sp. A1 ldh strain (MK2651) without plasmid was cultivated at 145 spm in $20 \mathrm{ml}$ liquid alginate media $\left[0.1 \% \mathrm{w} / \mathrm{v}\left(\mathrm{NH}_{4}\right)_{2} \mathrm{SO}_{4}, 0.1 \% \mathrm{w} / \mathrm{v} \mathrm{KH}_{2} \mathrm{PO}_{4}, 0.1 \%\right.$

$21 \mathrm{w} / \mathrm{v} \mathrm{Na} \mathrm{HPO}_{4}, 0.01 \% \mathrm{w} / \mathrm{v} \mathrm{MgSO}_{4} \cdot 7 \mathrm{H}_{2} \mathrm{O}, 0.01 \% \mathrm{w} / \mathrm{v}$ yeast extract $(\mathrm{pH} 8.0)$, and 25 $\mathrm{mg} / \mathrm{K} \mathrm{Kan}$ ] containing $0.8 \%$ (open circles), $2 \%$ (open squares), $3 \%$ (closed diamonds), $4 \%$ (open diamonds), $5 \%$ (closed triangles), or $6 \%$ (closed circles) $\mathrm{w} / \mathrm{v}$ alginate in

$24200-\mathrm{ml}$ Erlenmeyer flasks at $30^{\circ} \mathrm{C}$ for 6 days during which concentrations of pyruvate 25 (a) and alginate (b) and growth of the cultures (c) were measured. Averages and SD of 
1 three independent experiments are shown $(\mathrm{a}-\mathrm{c})$. (d) Aliquots $(5 \mu \mathrm{l})$ of cultures in the

2 indicated media, cultivated for the indicated number of days, were also analyzed by

3 TLC. Spots at the original positions represent alginate. The 0 -day culture of $5 \%$

4 alginate medium was too viscous to spot.

6 FIG. 4. Comparison of the Sphingomonas sp. A1 WT and ldh strains. WT (open triangles) and $l d h$ strains (closed triangles; MK2651 strain) were cultivated in $20 \mathrm{ml}$ liquid 5\% alginate media as in Fig. 3 for 6 days, during which concentrations of pyruvate (a), alginate (b), and D-lactate (c) and growth of the cultures (d) were measured. For the cultivation of WT strain, Kan was not included. Data of $l d h$ strain

11 were the same with those in Fig. 3. No production of L-lactate was detected. Means and SD of three independent cultivations are presented.

FIG. 5. Utilization of pyruvate (a) and tolerance to pyruvate (b) of the Sphingomonas sp. A1 WT strain, and simultaneous metabolism of alginate and pyruvate by the Sphingomonas sp. A1 ldh strain (c, d). (a) The WT strain was precultured as described in MATERIALS AND METHODS, collected, washed once with $2 \mathrm{mM}$ sodium-potassium phosphate ( $\mathrm{pH}$ 6.9), resuspended in the same buffer, and inoculated to reach an $\mathrm{OD}_{600}$ of 0.1 into $1.0 \mathrm{ml}$ of liquid $0.8 \%$ alginate $(\mathrm{Alg})$ medium, medium containing no alginate (None), or medium in which $0.8 \%$ alginate was replaced with

$210.8 \%(\mathrm{w} / \mathrm{v})$ of another carbon source: citrate (Cit), succinate (Suc), L-lactate (L-Lac),

22 D-Lactate (D-Lac), fumarate (Fum), L-malate (Mal), DL-isocitrate (isoCit), acetate 23 (Ace), glucose (Glc), or pyruvate (Pyr). The cells were cultivated for $24 \mathrm{~h}$ at $30^{\circ} \mathrm{C}$, 24 and $\mathrm{OD}_{600}$ was measured. (b) WT (open triangles) and $l d h$ (closed triangles) strains 25 were inoculated to reach $\mathrm{OD}_{600}$ of 0.1 into $1.0 \mathrm{ml}$ of liquid $0.8 \%$ alginate medium as 
1 above containing the indicated concentrations of pyruvate (final $\mathrm{pH}$ of the media; $\mathrm{pH}$

$28.0-8.2)$ as in Fig. 6a. The cells were cultivated for $24 \mathrm{~h}$ at $30^{\circ} \mathrm{C}$, and $\mathrm{OD}_{600}$ was

3 measured. (c) The ldh strain (MK2651) grown on alginate solid medium was

4 suspended in $2 \mathrm{mM}$ sodium-potassium phosphate and inoculated at an $\mathrm{OD}_{600}$ of 0.1

5 into $3.0 \mathrm{ml}$ of liquid medium containing $0.8 \%(\mathrm{w} / \mathrm{v})$ alginate (squares), $0.8 \%(\mathrm{w} / \mathrm{v})$

6 pyruvate (circles), or both $0.8 \%(\mathrm{w} / \mathrm{v})$ alginate and $0.8 \%(\mathrm{w} / \mathrm{v})$ pyruvate (triangles).

7 The cells were cultivated for $33 \mathrm{~h}$ at $30^{\circ} \mathrm{C}$, during which the concentration of pyruvate

8 (left; closed symbols), the concentration of alginate (left; open symbols), and $\mathrm{OD}_{600}$

9 (right) were measured. Means and maximum and minimum values of two independent

10 cultivations are presented. (d) The $l d h$ strain (MK2651) was cultivated as in Fig. 4 in

$1120 \mathrm{ml}$ liquid 5\% alginate medium without (closed triangles) or with (open triangles)

12 an initial pyruvate concentration of $0.5 \%$ [5.0 g/l]. Concentration of pyruvate (left),

13 concentration of alginate (middle), and $\mathrm{OD}_{600}$ (right) were measured. Data for the $l d h$

14 strain cultivated without initial pyruvate were the same as those shown in Fig. 3 and 4.

15 Means and SD of three independent cultivations are presented (a, b, d).

16 


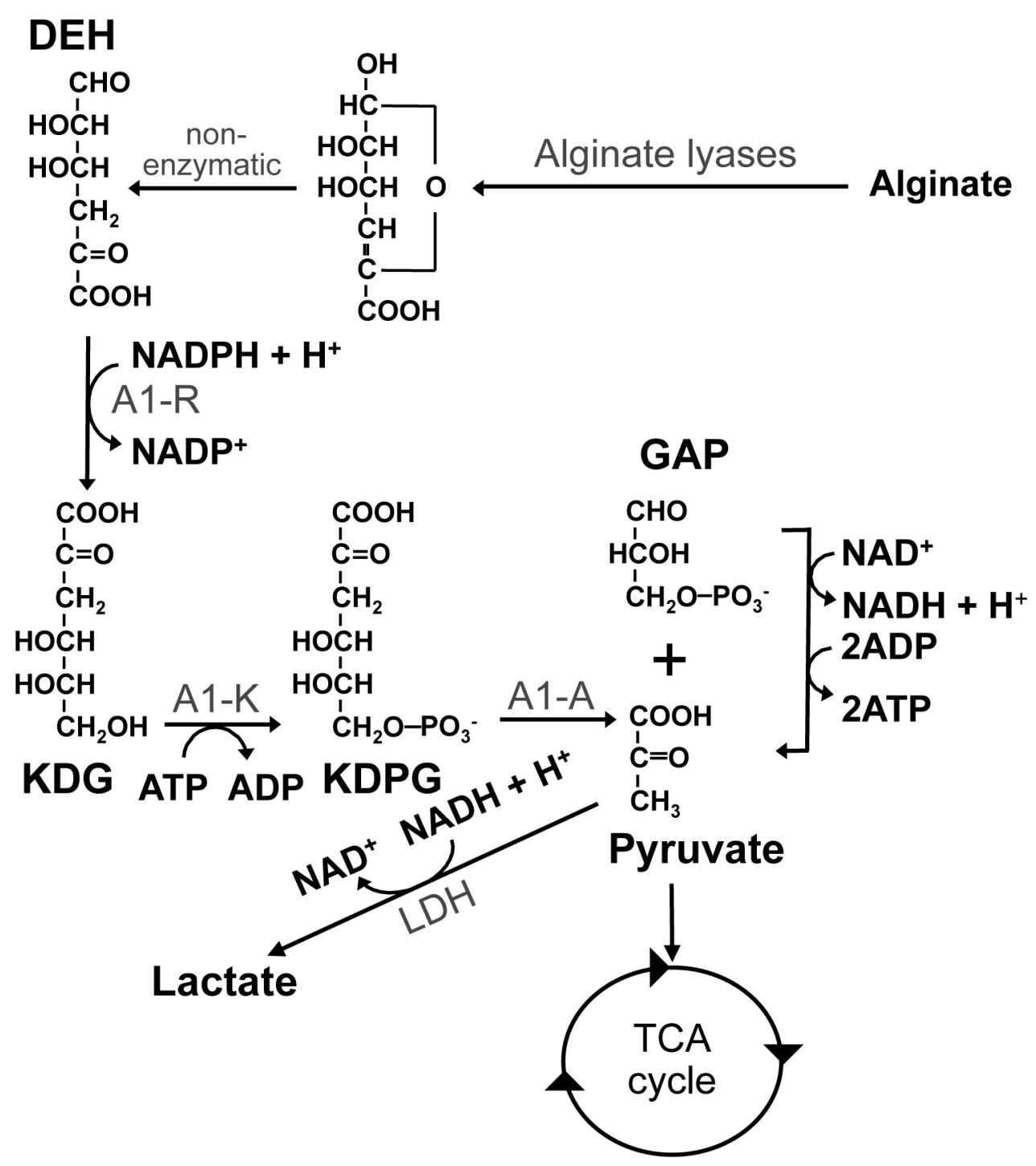

FIG. 1 

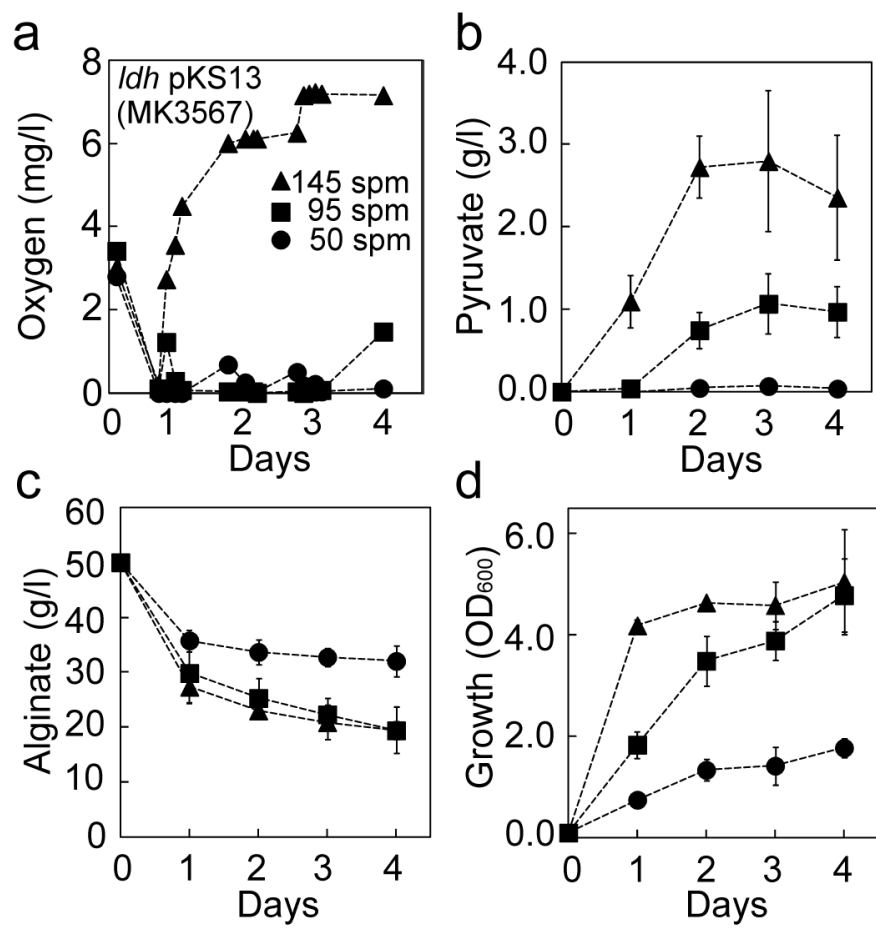

FIG. 2 
a

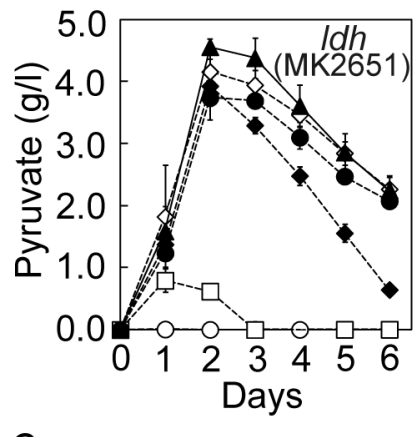

C

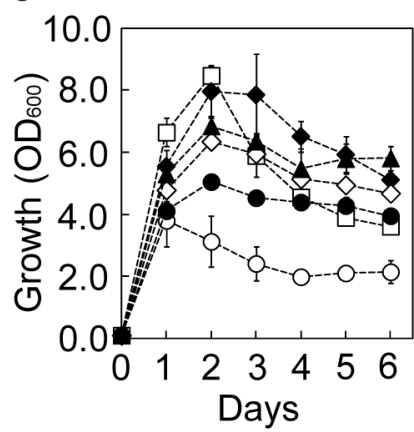

b

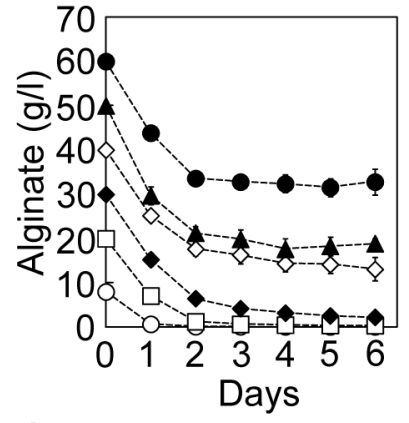

d

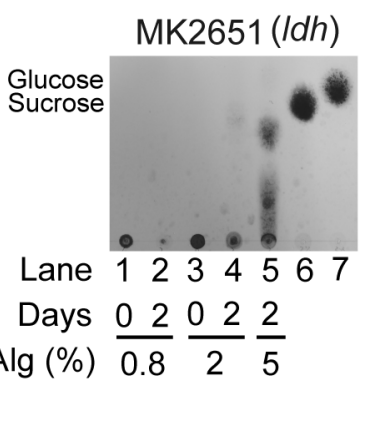

FIG. 3 

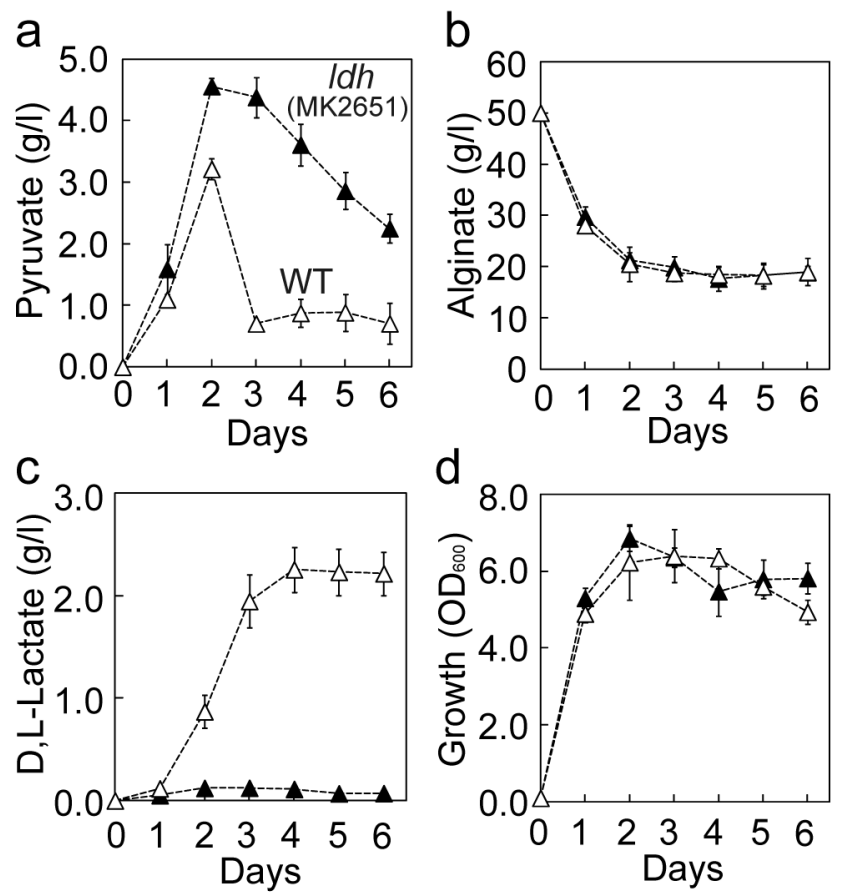

FIG. 4 
a

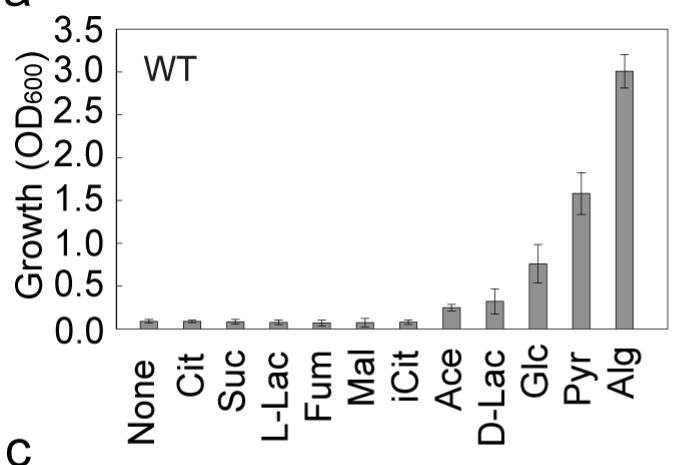

b

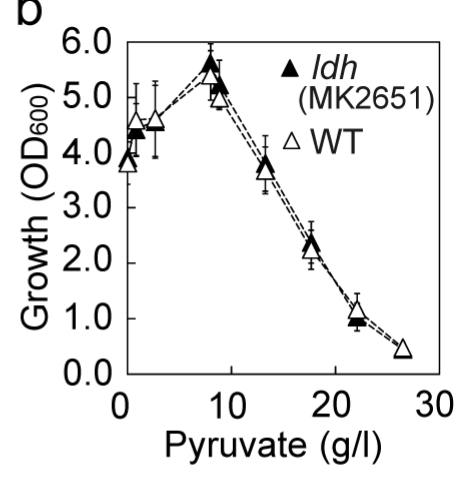

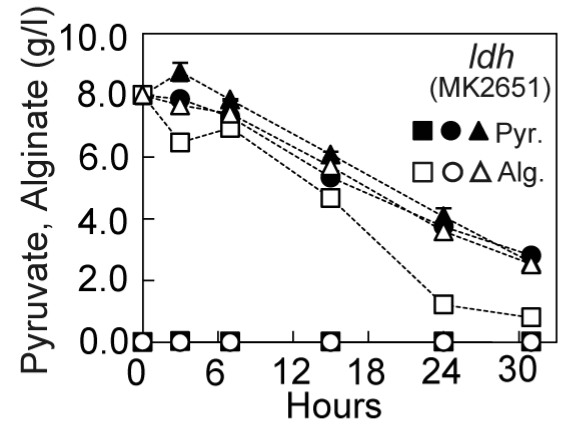
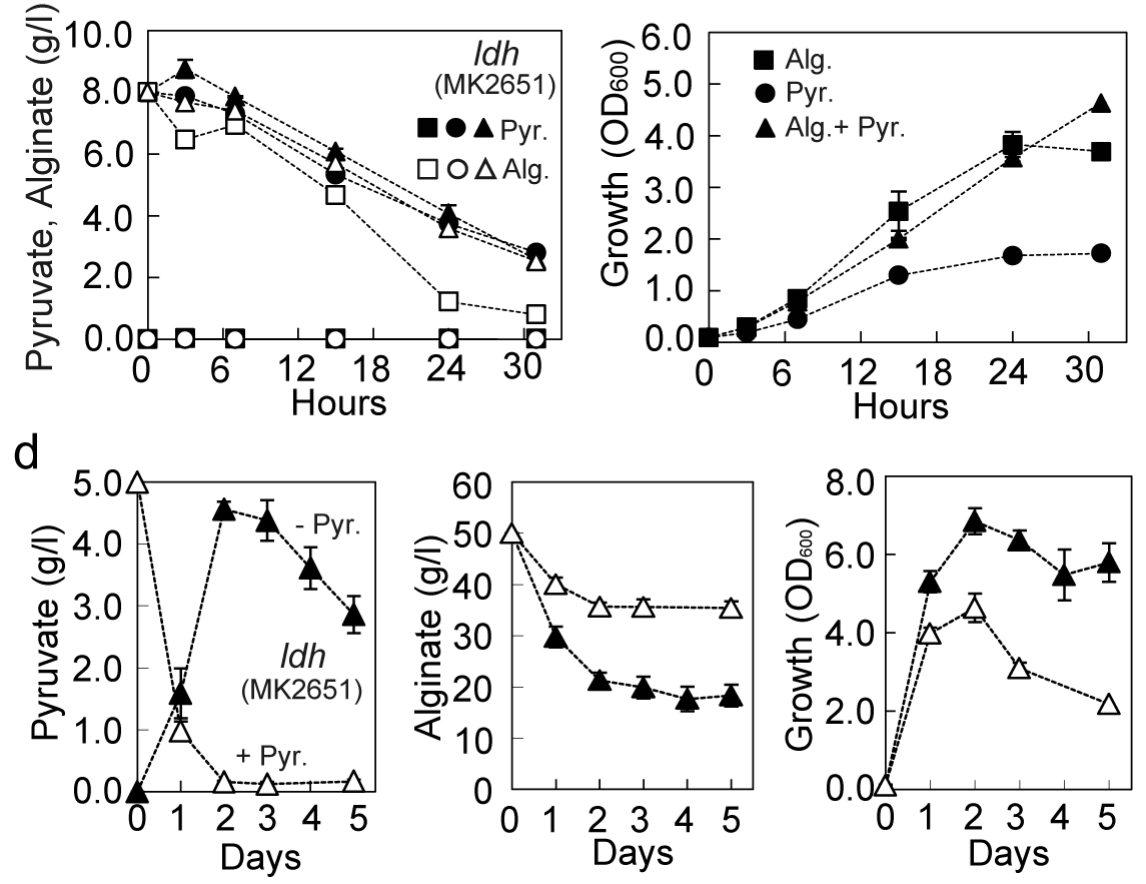

FIG. 5 
TABLE 1. Concentrations of metabolites in the supernatants of cultures ${ }^{a}$

\begin{tabular}{|c|c|c|c|}
\hline \multirow[b]{2}{*}{ Metabolites } & \multicolumn{3}{|c|}{ Concentrations $(\mu \mathrm{M})$} \\
\hline & 1 day & 2 days & 4 days \\
\hline Glyoxylic acid & 122 & 107 & 39 \\
\hline Glycolic acid & 106 & 64 & 72 \\
\hline Pyruvic acid & 1,148 & 20,227 & 26,218 \\
\hline Lactic acid & 43 & 33 & 53 \\
\hline 3-Hydroxybutyric acid & 24 & 100 & 645 \\
\hline Fumaric acid & 83 & 472 & 1,268 \\
\hline 2-Oxoisovaleric acid & 18 & 1,217 & 2,505 \\
\hline Succinic acid & 416 & 579 & 431 \\
\hline Malic acid & 175 & 525 & 1,379 \\
\hline 2-Oxoglutaric acid & 88 & 1,602 & 14,418 \\
\hline Glycerol 3-phosphate & 2.8 & 4.6 & 7.1 \\
\hline cis-Aconitic acid & 5.5 & 21 & 119 \\
\hline 3-Phosphoglyceric acid & 6.3 & 19 & 35 \\
\hline Isocitric acid & 4.7 & 10 & 66 \\
\hline Citric acid & 49 & 94 & 536 \\
\hline 6-Phosphogluconic acid & N.D. & N.D. & N.D. \\
\hline Sedoheptulose 7-phosphate & N.D. & N.D. & N.D. \\
\hline CMP & N.D. & N.D. & N.D. \\
\hline UMP & N.D. & N.D. & N.D. \\
\hline AMP & N.D. & N.D. & 12 \\
\hline GMP & N.D. & N.D. & N.D. \\
\hline CDP & N.D. & N.D. & N.D. \\
\hline UDP & 1.7 & 3.9 & 7.6 \\
\hline ADP & N.D. & N.D. & N.D. \\
\hline GDP & N.D. & N.D. & N.D. \\
\hline Gly & 1.0 & 2.8 & 0.7 \\
\hline Putrescine & 0.8 & 0.7 & 4.5 \\
\hline Ala & 18 & 62 & 1.1 \\
\hline$\beta$-Ala & N.D. & 1.6 & N.D. \\
\hline GABA & 0.4 & 0.7 & 0.7 \\
\hline Choline & 178 & 206 & 206 \\
\hline Ser & 11 & 9.0 & 3.0 \\
\hline Cytosine & 2.3 & 4.4 & 28 \\
\hline Creatinine & 0.11 & 0.13 & 0.7 \\
\hline Pro & 0.9 & 1.0 & 23 \\
\hline Val & 68 & 25 & 2.5 \\
\hline Betaine & 4.8 & 2.2 & 17 \\
\hline Homoserine & 0.7 & 0.6 & 0.06 \\
\hline Thr & 42 & 72 & N.D. \\
\hline Betaine aldehyde & 0.8 & 0.8 & 0.6 \\
\hline Ile & 1.9 & 0.2 & 0.12 \\
\hline Leu & 8.7 & 2.1 & 0.5 \\
\hline Asp & 0.6 & 0.3 & 0.8 \\
\hline
\end{tabular}


TABLE 1. Continued.

\begin{tabular}{lccc}
\hline Hypoxanthine & N.D. & N.D. & N.D. \\
Anthranilic acid & N.D. & N.D. & 0.3 \\
Ornithine & 0.4 & 0.2 & 0.13 \\
Adenine & N.D. & N.D. & N.D. \\
Gln & 1.2 & N.D. & N.D. \\
Lys & N.D. & N.D. & 0.4 \\
Glu & 2.0 & 0.6 & 4.2 \\
Met & N.D. & N.D. & N.D. \\
His & N.D. & N.D. & N.D. \\
Phe & N.D. & N.D. & N.D. \\
Arg & N.D. & N.D. & 0.4 \\
Tyr & N.D. & N.D. & N.D. \\
Thymidine & 9.1 & 13 & 46 \\
Cytidine & 0.2 & 0.3 & 1.6 \\
Adenosine & 1.1 & 0.3 & 0.3 \\
Inosine & 1.2 & 1.3 & 3.6 \\
Guanosine & 0.3 & 0.6 & 2.5 \\
S-Adenosylmethionine & 0.3 & 0.5 & 0.3 \\
\hline${ }^{a}$ Sphingomonas sp. A1 ldh strain carrying pKS13 (MK3567) was cultivated in $100 \mathrm{ml}$
\end{tabular}
liquid $5 \%$ alginate medium $\left[5 \% \mathrm{w} / \mathrm{v}\right.$ alginate, $0.1 \% \mathrm{w} / \mathrm{v}\left(\mathrm{NH}_{4}\right)_{2} \mathrm{SO}_{4}, 0.1 \% \mathrm{w} / \mathrm{v}$ $\mathrm{KH}_{2} \mathrm{PO}_{4}, 0.1 \% \mathrm{w} / \mathrm{v} \mathrm{Na}_{2} \mathrm{HPO}_{4}, 0.01 \% \mathrm{w} / \mathrm{v} \mathrm{MgSO}_{4} \cdot 7 \mathrm{H}_{2} \mathrm{O}, 0.01 \% \mathrm{w} / \mathrm{v}$ yeast extract $(\mathrm{pH}$ 8.0), $20 \mathrm{mg} / 1 \mathrm{Tet}$, and $25 \mathrm{mg} / \mathrm{Kan}$ ] in a $300-\mathrm{ml}$ Erlenmeyer flask at $30^{\circ} \mathrm{C}$ and $95 \mathrm{spm}$ for 1,2 , or 4 days. 
TABLE 2. Effect of initial alginate concentration on pyruvate production. ${ }^{\text {a }}$

\begin{tabular}{|c|c|c|c|c|c|c|c|c|}
\hline $\begin{array}{l}\text { Initial } \\
\text { alginate } \\
(\mathrm{g} / \mathrm{l})\end{array}$ & $\begin{array}{c}\Delta P \\
(\mathrm{~g} / \mathrm{l})^{\mathrm{b}}\end{array}$ & $\begin{array}{l}\text { Produ } \\
\text { ctivity } \\
\text { (mg/l/ } \\
\text { h) }\end{array}$ & $\begin{array}{c}\Delta S \\
(\mathrm{~g} / \mathrm{l})^{\mathrm{b}}\end{array}$ & $\begin{array}{c}\mathrm{Y}_{\mathrm{P} / \mathrm{S}} \\
(\mathrm{g} / \mathrm{g})^{\mathrm{c}}\end{array}$ & $\begin{array}{l}\text { Theoretical } \\
\text { yield }(\%)^{d}\end{array}$ & $\begin{array}{c}\Delta X \\
(\mathrm{~g} / \mathrm{l})^{\mathrm{b}}\end{array}$ & $\begin{array}{c}Y_{X / S} \\
(g / g)^{e}\end{array}$ & $\begin{array}{c}Y_{P / X} \\
(g / g)^{f}\end{array}$ \\
\hline 8 & 0.01 & 0.42 & 7.3 & 0.001 & 0.10 & 1.44 & 0.20 & 0.01 \\
\hline 20 & 0.79 & 32.9 & 12.9 & 0.06 & 6.1 & 2.53 & 0.20 & 0.31 \\
\hline 30 & 3.93 & 81.7 & 23.5 & 0.17 & 16.7 & 3.02 & 0.13 & 1.30 \\
\hline 40 & 4.16 & 86.7 & 22.3 & 0.19 & 18.6 & 2.41 & 0.11 & 1.72 \\
\hline 50 & 4.56 & 95.0 & 28.7 & 0.16 & 15.9 & 2.60 & 0.09 & 1.75 \\
\hline 60 & 3.74 & 77.9 & 26.4 & 0.14 & 14.2 & 1.92 & 0.07 & 1.95 \\
\hline $\begin{array}{c}50 \\
(\mathrm{WT})^{\mathrm{g}}\end{array}$ & 3.21 & 67.1 & 29.5 & 0.11 & 10.9 & 2.37 & 0.08 & 1.36 \\
\hline
\end{tabular}

${ }^{\mathrm{a}}$ Data were calculated based on data in Fig. 4. The $l d h$ and WT strains were cultivated at $145 \mathrm{spm}$ in $20 \mathrm{ml}$ liquid $5 \%$ alginate media [5\% w/v alginate, $0.1 \% \mathrm{w} / \mathrm{v}$ $\left(\mathrm{NH}_{4}\right)_{2} \mathrm{SO}_{4}, 0.1 \%$ w/v $\mathrm{KH}_{2} \mathrm{PO}_{4}, 0.1 \%$ w/v $\mathrm{Na}_{2} \mathrm{HPO}_{4}, 0.01 \%$ w/v $\mathrm{MgSO}_{4} \cdot 7 \mathrm{H}_{2} \mathrm{O}$, $0.01 \% \mathrm{w} / \mathrm{v}$ yeast extract $(\mathrm{pH} 8.0)]$ in $200-\mathrm{ml}$ Erlenmeyer flasks.

${ }^{\mathrm{b}}$ Concentrations of produced pyruvate $(\Delta P)$, productivity $(\mathrm{mg} / \mathrm{l} / \mathrm{h})$, consumed alginate $(\Delta S)$, or CDW $(\Delta X)$ in 1-day culture under initial alginate of 8 and $20 \mathrm{~g} / 1$, or those in 2-day culture under initial alginate of $30,40,50$, and $60 \mathrm{~g} / \mathrm{l}$.

${ }^{\mathrm{c}}$ Yield of pyruvate produced $(\Delta P)$ per alginate consumed $(\Delta S)(\mathrm{g} / \mathrm{g})$.

${ }^{\mathrm{d}}$ Theoretical yield of pyruvate produced $(\Delta P)$ per alginate consumed $(\Delta S)(\%)$. Theoretical yield was taken to be $100 \%$ when $100 \mathrm{~g}$ pyruvate was produced from 100 
$\mathrm{g}$ consumed alginate, because 2 mol of pyruvate (MW of 88) is theoretically produced from $1 \mathrm{~mol}$ of DEH (MW of 176) (Fig. 1).

e Yield of CDW $(\Delta X)$ per alginate consumed $(\Delta S)(\mathrm{g} / \mathrm{g})$.

${ }^{\mathrm{f}}$ Yield of pyruvate produced $(\Delta P)$ per CDW $(\Delta X)(\mathrm{g} / \mathrm{g})$.

${ }^{\mathrm{g}}$ Sphingomonas sp. A1 WT cells were cultivated in the presence of $50 \mathrm{~g} / \mathrm{l}$ alginate. 